\title{
Early Detection of Metabolic Abnormalities in Patients with Newly Diagnosed Schizophrenia on Atypical Antipsychotics
}

\author{
D. Rochlani ${ }^{1}$, S. Lahariya², S.K. Bansal ${ }^{3}$ \\ ${ }^{1}$ Department of Biochemistry, SGT Medical College, Gurugram, Haryana, India. ${ }^{2}$ Department of Psychiatry, Gwalior Mansik \\ Arogyashala, Gwalior, India. ${ }^{3}$ Department of Biochemistry, SGT Medical College, Gurugram, Haryana, India.
}

\section{ABSTRACT}

\section{BACKGROUND}

Early detection of metabolic abnormalities in patients with schizophrenia is of importance for treatment planning and policymaking. This study aimed to assess the progress of metabolic abnormalities in newly diagnosed schizophrenia patients, who were on atypical antipsychotic treatment, by estimating their six months incidence of metabolic syndrome.

\section{METHODS}

This hospital based follow up study was conducted through a collaboration of a Medical College and Mental Hospital from Oct 2016 to Sep 2017. The authors screened all patients who attended the OPD during the study period. ICD 10 criteria were applied to confirm the diagnosis of schizophrenia. All study subjects were also screened for the presence of metabolic syndrome at baseline. Their anthropometric measurements and biochemical parameters were recorded at regular intervals to detect metabolic abnormalities.

\section{RESULTS}

Total 74 patients who completed 6 months follow up, were included in the study. Mean age of our study sample was 29.9. Of all patients, $34(45.9 \%)$ were females and 40 (54\%) were males; 53 (71.6\%) were married, 51(68.9\%) patients already had 1 or 2 altered metabolic parameters at baseline. 21 (28.3\%) patients developed metabolic syndrome at the end of 6 months follow up. Metabolic syndrome was more common in the female population and in those who had any altered metabolic component at baseline.

\section{CONCLUSIONS}

Patients with schizophrenia who are on atypical antipsychotics are at increased risk of developing metabolic syndrome. Metabolic abnormalities are detectable as early as within 6 months and may progress rapidly and convert into metabolic syndrome at 6 months follow up. These findings support the importance of assessing and monitoring of metabolic abnormalities in schizophrenia patients.

\section{KEY WORDS}

Schizophrenia, Metabolic Syndrome, Atypical Antipsychotics

\author{
Corresponding Author: \\ Dr. Sanjay Lahariya, \\ Department of Psychiatry, \\ Gwalior Mansik Arogyashala, \\ Gwalior, India. \\ E-mail: drsan24@gmail.com
}

DOI: $10.14260 / j e m d s / 2019 / 700$

Financial or Other Competing Interests: None.

How to Cite This Article:

Rochlani D, Lahariya S, Bansal SK. Early detection of metabolic abnormalities in patients with newly diagnosed schizophrenia on atypical antipsychotics. J. Evolution Med. Dent. Sci. 2019;8(43): 3229-3233,

DOI:

Submission 09-08-2019,

Peer Review 12-10-2019,

Acceptance 18-10-2019,

Published 28-10-2019. 


\section{BACKGROUND}

Schizophrenia is one of the most severe mental disorders and is among the twenty leading causes of disability worldwide. ${ }^{1}$ Increased mortality in schizophrenia patients have been reported by several studies. ${ }^{2-4}$ This rate is two to three times higher in these patients as compared with general population $^{5,6}$ and leading to death 1-2 decades earlier.4-8 Diseases related to cardiovascular disorders are commonly associated with mortality in schizophrenia patients. ${ }^{9}$ It has been reported that schizophrenia patients are on greater risk of cardiovascular disease and diabetes type $2.3,6,10$ Risk factors for CVD are linked with metabolic abnormalities. $1,5,6,8$ Physical inactivity, sedentary lifestyle, malnutrition, duration of illness are some reasons to cause metabolic abnormalities. ${ }^{4}$ It accounts $34 \%$ of deaths in male and $31 \%$ of deaths in female patients. $^{3}$ Nowadays presence of metabolic abnormalities is a greater issue in patients with mental illness and are 2 to 3 fold higher in these patients.11,12 These abnormal clinical and metabolic findings are collectively termed as metabolic syndrome, including visceral adiposity (measured by waist circumference), high fasting glucose, increased triglyceride level and low high-density lipoprotein cholesterol level. ${ }^{5}$

There are different organizations that used different factors to define metabolic syndrome. According to the National Cholesterol Education Program Adult Treatment Panel III (NCEP: ATP III) criteria (2001), any three or more of the following: Waist circumference $>102 \mathrm{~cm}$ in men and $>88$ $\mathrm{cm}$ in women, Triglycerides $\geq 150 \mathrm{mg} / \mathrm{dl}$., HDL-cholesterol $<40 \mathrm{mg} / \mathrm{dl}$ in men and $<50 \mathrm{mg} / \mathrm{dl}$ in women, BP $\geq 130 / 85$ $\mathrm{mmHg}$., Fasting glucose $\geq 110 \mathrm{mg} / \mathrm{dl}$, are factors to detect metabolic syndrome. ${ }^{13}$ Antipsychotics are the mainstay of treatment of schizophrenia, certain atypical antipsychotics have been reported to produce substantial weight gain and an increased risk for insulin resistance, hyperglycaemia, dyslipidaemia and T2DM. Recently, there has been a growing interest in metabolic abnormalities among psychiatric patients receiving some Second generation antipsychotics (SGAs). ${ }^{14,15}$ The prevalence of metabolic syndrome is almost double in patients with schizophrenia, the use of atypical antipsychotics further increases the risk. ${ }^{16}$ Nevertheless has the awareness of schizophrenia patients risk to develop MetS resulted in treatment guidelines which demand the regular monitoring of relevant physical and laboratory parameters; in several countries these are meanwhile regarded clinical standard of care. ${ }^{17}$

This study was conducted to assess the alteration of metabolic abnormalities at baseline and 6 months of treatment with atypical antipsychotic medications and to detect the development of metabolic syndrome during the course of treatment.

\section{METHODS}

This is a hospital based follow up study where subjects identified at the beginning were followed up for 6 months. This study was conducted in the Department of Psychiatry, Mansik Arogyashala, Gwalior and Department of
Biochemistry, SGT Medical College Gurgaon between Oct2016 and Sept- 2017.

\section{Study Subjects}

Total 74 newly diagnosed schizophrenia patients were included in study and were screened to assess the progress of abnormalities in metabolic parameters, initiated on atypical antipsychotic drugs under the supervision of specialist psychiatrist.

\section{Inclusion and Exclusion Criteria}

Newly diagnosed drug naïve patients of age 20 to 40 years were included in the study, diagnosis of schizophrenia was made as per the ICD-10 diagnostic criteria ${ }^{18}$. Patients who were already on antipsychotic drugs and already have 3 or more abnormal metabolic components before entering in study and other physical illnesses imposing the risk of metabolic syndrome in the future were excluded from study.

\section{Data Collection \& Tools}

This study was conducted in 2 phases. In the first phase our primary research objective was to assess abnormalities in metabolic components at $6^{\text {th }}$ month of treatment and to compare them from baseline. In second phase, as a secondary outcome the authors assessed the prevalence of metabolic syndrome after six months treatment, as defined by Adult Treatment Panel III in 2001 (NCEP-ATP III).Patient demographics and characteristics were recorded Metabolic parameters and Anthropometric measurements (waist circumference, weight, height and Body Mass Index, Blood Pressure) were assessed at baseline and at the end of $6^{\text {th }}$ month. Waist circumference was measured by using measuring tap over the midpoint between lowest rib (costal margin) and iliac crest, body weight of each patient was recorded by adult balance and height was taken by using stadiometer, BMI (body mass index) was calculated by weight in kilograms divided by square of height in meters. Digital blood pressure device was used to measure blood pressure. Fasting venous blood samples were drawn in fluoride/Plain vials. Plasma/ serum was separated to assess the blood levels of triglycerides, HDL-cholesterol, total cholesterol and fasting blood sugar level were assessed by using ERBA diagnostic kit.

\section{Statistical Analysis}

Student paired ' $\mathrm{t}$ ' test was used to compare means of metabolic abnormalities at baseline and after 6 months of treatment. Chi-square test was used to compare metabolic changes between patients of metabolic syndrome with the non-metabolic syndrome. Data were analysed by IBM-SPSS 20. The results were considered significant if $\mathrm{p}<0.05$.

\section{Ethical Approval and Patient Consent}

The study was approved by the ethical committee. Informed consent was taken from all patients or their relatives before inclusion in the study.

\section{RESULTS}

Total of 74 patients who met inclusion criteria were included in the study and followed up for six months after starting 
antipsychotic treatment. Sociodemographic profile of study sample shows $45.9 \%$ population were female and $54 \%$ were male and their mean education in years was 5.62 and $71.6 \%$ were married, $16.2 \%$ were employed and nearly equal belongs to the rural and urban area. In this study, significant alteration in metabolic components was seen at 6 months of antipsychotic treatment in terms of increased Body Mass Index (BMI), systolic blood pressure, triglycerides level and fasting glucose level, and on the other hand, significant number of patients had decreased HDL level as compared to baseline. (Figure. 1)

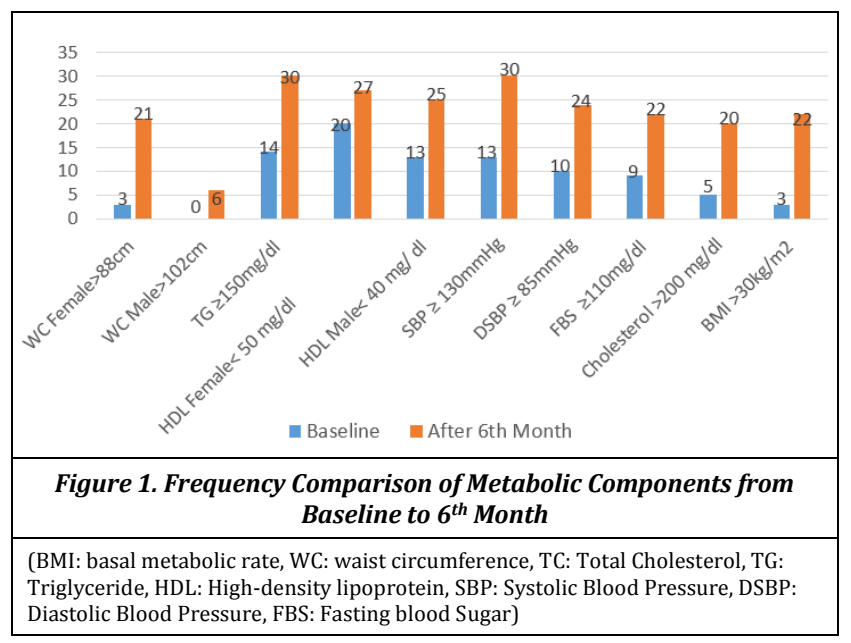

After completion of 6 months follow up mean values of altered metabolic parameters were compared with the mean values of metabolic parameters at baseline. The paired t-test was applied to find out statistically significant difference. Result of this statistical analysis was suggestive of increased level of mean value of triglyceride, fasting blood sugar, cholesterol, waist circumference, blood pressure, weight and BMI from baseline value and it was statistically significant and the level of mean value of HDL showed statistically significant fall from baseline HDL level. (See Table no. 1)

\begin{tabular}{|c|c|c|c|c|}
\hline Sr. No. & Variables & $\begin{array}{c}\text { Baseline } \\
(\mathrm{N}=74) \\
(\mathrm{Mean} \pm \mathrm{SD}) \\
\end{array}$ & $\begin{array}{c}{\text { After } 6^{\text {th }} \text { Month }}^{(\mathrm{N}=74)} \\
(\text { Mean } \pm \text { SD }) \\
\end{array}$ & \begin{tabular}{|c|} 
Paired t-Test \\
Significant \\
p $<0.05$ \\
\end{tabular} \\
\hline 1 & $\begin{array}{c}\mathrm{WC} \\
\mathrm{F}>88 \mathrm{~cm} \\
\mathrm{M}>102 \mathrm{~cm}\end{array}$ & $\begin{array}{l}\text { F- } 76.1 \pm 11.0 \\
M-79.5 \pm 9.0\end{array}$ & $\begin{array}{l}\text { F- } 90.5 \pm 10.7 \\
\text { M- } 90.2 \pm 12.8\end{array}$ & $\begin{array}{l}.000 \\
.000\end{array}$ \\
\hline 2 & $\begin{array}{c}\uparrow \mathrm{TG} \\
\geq 150 \mathrm{mg} / \mathrm{dl}\end{array}$ & $115.0 \pm 42.9$ & $166.4 \pm 82.9$ & .000 \\
\hline 3 & $\begin{array}{c}\downarrow \mathrm{HDL} \\
\mathrm{F}<50 \mathrm{mg} / \mathrm{dlM}<40 \\
\mathrm{mg} / \mathrm{dl}\end{array}$ & $\begin{array}{l}\text { F- } 47.2 \pm 7.6 \\
\text { M- } 42.8 \pm 6.6\end{array}$ & $\begin{array}{l}\text { F- } 39.9 \pm 9.8 \\
\text { M- } 36.3 \pm 8.5\end{array}$ & .000 \\
\hline 4 & $\begin{array}{c}\text { SBP } \\
\geq 130 \mathrm{mmHg} \\
\end{array}$ & $116.3 \pm 13.2$ & $123.8 \pm 13.9$ & .000 \\
\hline & $\begin{array}{c}\text { DSBP } \\
\geq 85 \mathrm{mmHg} \\
\end{array}$ & $74.7 \pm 10.3$ & $80.5 \pm 11.8$ & .000 \\
\hline 5 & $\begin{array}{c}\text { FBS } \\
\geq 110 \mathrm{mg} / \mathrm{dl}\end{array}$ & $94.2 \pm 23.8$ & $106.0 \pm 28.3$ & .000 \\
\hline 6 & $\begin{array}{c}\uparrow \mathrm{TC} \\
>200 \mathrm{mg} / \mathrm{dl} \\
\end{array}$ & $150.0 \pm 37.7$ & $176.9 \pm 45.9$ & .000 \\
\hline 7 & $\begin{array}{c}\uparrow \mathrm{BMI} \\
>30 \mathrm{Kg} / \mathrm{m}^{2} \\
\end{array}$ & $23.1 \pm 4.3$ & $27.4 \pm 5.3$ & .000 \\
\hline \multicolumn{5}{|c|}{$\begin{array}{l}\text { Table 1. Comparison of Mean Values of Altered Metabolic Parameters at } \\
\text { Baseline and at the End of } 6^{\text {th }} \text { Month of Antipsychotic Therapy }(N=74)\end{array}$} \\
\hline \multicolumn{5}{|c|}{$\begin{array}{l}\text { (BMI: basal metabolic rate, WC: waist circumference, TC: Total Cholesterol, TG: } \\
\text { Triglyceride, HDL: High-density lipoprotein, SBP: Systolic Blood Pressure, DSBP: } \\
\text { Diastolic Blood Pressure, FBS: Fasting blood Sugar) }\end{array}$} \\
\hline
\end{tabular}

In this study, it was found that $28.3 \%$ patients developed metabolic syndrome out of which $22.5 \%$ were male and $35.2 \%$ were female. Incidence of metabolic syndrome was found to be higher in female patients compared to male patients. It was also noted that $76 \%$ of patients who had developed metabolic syndrome already had 2 out of 5 altered metabolic components at baseline before starting treatment.

\begin{tabular}{|c|c|c|c|c|}
\hline $\begin{array}{c}\text { Sr. } \\
\text { No. }\end{array}$ & Variables & $\begin{array}{c}\text { Metabolic } \\
\text { Syndrome } \\
\text { Present N=21 }\end{array}$ & $\begin{array}{c}\text { Without } \\
\text { Metabolic } \\
\text { Syndrome } \\
\text { Present N=53 }\end{array}$ & $\begin{array}{c}\text { Chi-Square } \\
\text { Test } \\
\text { p-Value }\end{array}$ \\
\hline 1 & $\begin{array}{c}\mathrm{WC} \\
\mathrm{F}>88 \mathrm{~cm} \\
\mathrm{M}>102 \mathrm{~cm}\end{array}$ & $\begin{array}{c}\mathrm{F}-10 / 12(83.3 \%) \\
\mathrm{M}-05 / 09(55.6 \%)\end{array}$ & $\begin{array}{c}\mathrm{F}-11 / 22(50 \%) \\
\mathrm{M}-1 / 31(3.2 \%)\end{array}$ & $\begin{array}{c}>.05 \\
<.05\end{array}$ \\
\hline 2 & $\begin{array}{c}\uparrow \mathrm{TG} \\
\geq 150 \mathrm{mg} / \mathrm{dl}\end{array}$ & $19(90.5 \%)$ & $11(20.8 \%)$ & $<.05$ \\
\hline 3 & $\begin{array}{c}\downarrow \mathrm{HDL} \\
\mathrm{F}<50 \mathrm{mg} / \mathrm{dlM} \\
<40 \mathrm{mg} \mathrm{dl}\end{array}$ & $\begin{array}{c}\mathrm{F}-11 / 12(91.7 \%) \\
\mathrm{M}-08 / 09(88.9 \%)\end{array}$ & $\begin{array}{c}\mathrm{F}-16 / 22(72.7 \%) \\
\mathrm{M}-17 / 31(54.8 \%)\end{array}$ & $\begin{array}{c}>.05 \\
>.05\end{array}$ \\
\hline 4 & $\begin{array}{c}\mathrm{SBP} \\
\geq 130 \mathrm{mmHg}\end{array}$ & $18(85.7 \%)$ & $12(22.6 \%)$ & $<.05$ \\
\hline $\begin{array}{c}\mathrm{DSBP} \\
25 \mathrm{mmHg}\end{array}$ & $16(76.2 \%)$ & $08(15.1 \%)$ & $<.05$ \\
\hline 5 & $\begin{array}{c}\mathrm{FBS} \\
\geq 110 \mathrm{mg} / \mathrm{dl}\end{array}$ & $13(61.9 \%)$ & $09(17.0 \%)$ & $<.05$ \\
\hline 6 & $\begin{array}{c}\uparrow \mathrm{TC} \\
>200 \mathrm{mg} / \mathrm{dl}\end{array}$ & $06(28.6 \%)$ & $14(26.4 \%)$ & $>.05$ \\
\hline 7 & $\begin{array}{c}\uparrow \mathrm{BMI} \\
>30 \mathrm{Kg} / \mathrm{m}^{2}\end{array}$ & $13(61.9 \%)$ & $09(17.0 \%)$ & $<.05$ \\
\hline
\end{tabular}

Table 2. Comparison of Parameters between Patients with and without Metabolic Syndrome after 6 Months of Treatment $(n=74)$ (BMI: basal metabolic rate, WC: waist circumference, TC: Total Cholesterol, TG: Triglyceride, HDL: High-density lipoprotein, SBP: Systolic Blood Pressure, DSBP: Diastolic Blood Pressure, FBS: Fasting blood Sugar)

At the $6^{\text {th }}$ month Chi Sq. test was applied to study the alteration in metabolic components in the metabolic and nonmetabolic group. It was observed that level of TG, FBS, SBP, DSBP were significantly higher in metabolic group. In addition, significantly difference in WC was also seen in male patients who develop metabolic syndrome. In this study, it was found that risk of metabolic syndrome was higher in female population as well as in those patients, who already had 1 or 2 altered metabolic parameters at baseline. Age of onset and severity of illness in terms of hospitalisation were not found to be the significant risk factors.

\section{DISCUSSION}

In this study, it was found that $21(28.3 \%)$ patients of newly diagnosed schizophrenia, receiving atypical antipsychotics developed metabolic syndrome at six-month follow-up. In metabolic syndrome dyslipidaemia and glucose dysregulation are key components along with weight gain and it can be highly seen in patients treated with antipsychotic drugs. Similar results are found in this study and this was also supported by the several other studies ${ }^{19}$ which reported significantly higher (17.8\%) prevalence of metabolic syndrome among schizophrenia patients treated with atypical antipsychotic drugs.

Another study ${ }^{20}$ which reviewed the rate of metabolic syndrome in Thai schizophrenia patients associated with antipsychotics, the prevalence rate of metabolic syndrome varied from $15.4 \%$ to $23.9 \%$. By applying the IDF criteria and $20.5 \%$ to $30.5 \%$, by the updated ATP III criteria. So, it can be suggested that the prevalence of metabolic syndrome varies according to the population and criteria applied.

In this study, it was also seen that 74 subjects started on atypical antipsychotic therapy, out of them 51 (68.9\%) were those who, already had one or two metabolic abnormalities at baseline before starting treatment, but didn't qualify the 
criteria for metabolic syndrome. After six months follow up, $21(28.3 \%)$ Patients developed metabolic syndrome and all of them were those patients who already had 1 or 2 abnormal metabolic components at baseline, by this it may be suggested that patients with 1 or 2 abnormal metabolic components at baseline are on greater chance to develop metabolic syndrome. It is supported by a study which reported that $20.0 \%$ schizophrenic patients receiving longterm antipsychotic treatment developed metabolic syndrome and all of them were part of the participants who already had 2 metabolic syndrome components at baseline.

In the present study, we also found that prevalence of metabolic syndrome was more in female schizophrenic patient as compared to male population and it was supported by several studies $21,22,23$. In this study $97 \%$ patients showed weight gain after 6 months of antipsychotic drug therapy and there was statistically significant rise in number of patients with high BMI from 3 to $22(\mathrm{p}<0.05)$ and there was also statistically significant difference noted in number of patients having increased BMI in patients who developed metabolic syndrome $(61.9 \%)$ as compared with non-metabolic group $(17 \%)$. So BMI can also be considered predictor of metabolic syndrome along with components of metabolic syndrome. Similarly, it was reported in earlier study. ${ }^{21,22}$

It is stated that after 6 months of antipsychotic treatment frequency of abdominal obesity was higher in female patients compared with male patients (See Figure -1). Although significant change $(p<.05)$ in waist circumference was seen in male patients when compared metabolic group (55.6\%) with non-metabolic group (3.2\%) (See table no. 2). Some earlier studies also supported this statement and also reported that abdominal obesity is most prevalent component of metabolic syndrome in schizophrenia patients. ${ }^{22,24}$

Number of Patients with raised fasting blood sugar level increased from 9 to $22(\mathrm{p}<0.05)$ during the period of six month follow up, in addition significant difference in raised blood sugar level was also seen in patients with metabolic group (61.9\%) when compared to non-metabolic (17.0\%) group (Table 2), although high fasting blood sugar level was found as least common metabolic component for development of metabolic syndrome, similar results are also reported in other studies.

In this study 14 patients had high triglyceride level at baseline, and this number raised at significant level ( $p<0.05$ ) up to 30 patients in study population and there was also a significant difference in number of patients with raised triglyceride level in metabolic group (90.5\%) as compared to non-metabolic (20.8\%) group after 6 months of treatment. At baseline there were 13 male and 20 females with decreased HDL cholesterol level, this figure raised to become 25 male ( $p$ $<0.05)$ and 27 females $(\mathrm{p}<0.05)$ after 6 months. Therefore, it can be suggested that low HDL is the most prevalent component of metabolic syndrome which imposes higher risk for cardiac diseases. This was supported by a study ${ }^{24}$ and some studies reported low HDL component is the second most component.

Although, we did not assess and compare the metabolic risk of individual atypical antipsychotic drug and it seems to be the limitation in our study. However many studies have been conducted in this regard and this appeared a wellknown fact that few atypical antipsychotics i.e. olanzapine, risperidone and clozapine have greater potential to develop metabolic abnormalities in any individual, but despite knowing the potential greater risk we may not avoid the use of these drugs because of their good efficacy and excellent result in clinical practice. Basically, our primary focus was to detect early metabolic changes, so the prevention and treatment of metabolic comorbidities can be started as early as possible.

\section{Implications}

The psychiatrist needs to be aware of the potential metabolic side effects of antipsychotic medication and to include them in the risk/benefit assessment, Multidisciplinary assessment of psychiatric and medical conditions is needed, Psychiatric treatment facilities should offer and promote healthy lifestyle interventions. The somatic treatments offered to people with severe and enduring mental illness should be at par with general health care in the non-psychiatrically ill population, therefore the quality and expectancy of life of schizophrenia patients can be improved.

\section{CONCLUSIONS}

Patients of schizophrenia receiving long-term antipsychotics are likely to develop metabolic abnormalities as early as within 3 months of treatment. These abnormalities may rapidly progress to metabolic syndrome within 6 months of follow-up. These findings support the importance of assessing and monitoring metabolic parameters in schizophrenic patients, especially who are on atypical antipsychotics.

\section{REFERENCES}

[1] Sicras-Mainar A, Maurino J, Ruiz-Beato E, et al. Prevalence of metabolic syndrome according to the presence of negative symptoms in patients with schizophrenia. Neuropsychiatric Disease and Treatment 2015;11:51-7.

[2] Kraemer S, Minarzyk A, Forst T, et al. Prevalence of metabolic syndrome in patients with schizophrenia, and metabolic changes after 3 months of treatment with antipsychotics-results from a German observational study. BMC Psychiatry 2011;11(1):173.

[3] Riordan HJ, Antonini P, Murphy MF. Atypical antipsychotics and metabolic syndrome in patients with schizophrenia: risk factors, monitoring, and healthcare implications. American Health \& Drug Benefits 2011;4(5):292-302.

[4] Malhotra N, Grover S, Chakrabarti S, et al. Metabolic syndrome in schizophrenia. Indian Journal of Psychological Medicine 2013;35(3):227-40.

[5] Mitchell AJ, Vancampfort D, De Herdt A, et al. Is the prevalence of metabolic syndrome and metabolic abnormalities increased in early schizophrenia? A comparative meta-analysis of first episode, untreated and treated patients. Schizophrenia Bulletin 2013;39(2):295-305. 
[6] De Hert M, Schreurs V, Vancampfort D, et al. Metabolic syndrome in people with schizophrenia: a review. World Psychiatry 2009;8(1):15-22.

[7] Grundy SM. Hypertriglyceridemia, insulin resistance and the metabolic syndrome. The American Journal of Cardiology 1999;83(9B):25F-9F.

[8] Chiu CC, Chen $\mathrm{CH}$, Chen BY, et al. The time-dependent change of insulin secretion in schizophrenic patients treated with olanzapine. Progress in Neuropsychopharmacology and Biological Psychiatry 2010;34(6):866-70.

[9] Meyer JM. The metabolic syndrome and schizophrenia: clinical research update. Psychiatr Times 2007;24(2):16.

[10] Papanastasiou E. Interventions for the metabolic syndrome in schizophrenia: a review. Therapeutic Advances in Endocrinology and Metabolism 2012;3(5):141-62.

[11] Srisurapanont M, Likhitsathian S, Boonyanaruthee V, et al. Metabolic syndrome in Thai schizophrenic patients: a naturalistic one-year follow-up study. BMC Psychiatry 2007;7:14.

[12] Sankaranarayanan A, Castle D. Monitoring and managing metabolic syndrome in persons with mental illness. AP J Psychol Med 2012;13(1):9-13.

[13] Kassi E, Pervanidou P, Kaltsas G, et al. Metabolic syndrome: definitions and controversies. BMC Medicine 2011;9(1):48.

[14] Meyer JM, Stahl SM. The metabolic syndrome and schizophrenia. Acta Psychiatrica Scandinavica 2009;119(1):4-14.

[15] Stahl SM, Mignon L, Meyer JM. Which comes first: atypical antipsychotic treatment or cardiometabolic risk? Acta Psychiatrica Scandinavica 2009;119(3):171-9.

[16] De Hert M, Schreurs V, Sweers K, et al. Typical and atypical antipsychotics differentially affect long-term incidence rates of the metabolic syndrome in firstepisode patients with schizophrenia: a retrospective chart review. Schizophrenia Research 2008;101(13):295-303.
[17] NICE (National Collaborating Centre for Mental Health, National Institute of Clinical Excellence): Schizophrenia: Core interventions in the treatment and management of Schizophrenia in primary and secondary care. Clinical Practice Guideline $82 . \quad$ NICE 2009. [http://www.nice.org.uk/nicemedia/ pdf/CG82FullGuideline.pdf], (accessed 26 Jan 2010).

[18] Gautam S, Meena PS. Drug-emergent metabolic syndrome in patients with schizophrenia receiving atypical (second-generation) antipsychotics. Indian J Psychiatry 2011;53(2):128-33.

[19] Owusu-Ansah A, Panyin AB, Obirikorang C, et al. Metabolic syndrome among schizophrenic patients: a comparative cross-sectional study in the middle belt of Ghana. Schizophrenia Research and Treatment 2018;2018:6542983.

[20] Udomratn P. Metabolic syndrome in psychiatric patients treated with antipsychotic drugs in Thailand. Clinical Psychopharmacology and Neuroscience 2010;8(2):7983.

[21] Grover S, Aggarwal M, Dutt A, et al. Prevalence of metabolic syndrome in patients with schizophrenia in India. Psychiatry Research 2012;200(2-3):1035-7.

[22] Huang MC, Lu ML, Tsai CJ, et al. Prevalence of metabolic syndrome among patients with schizophrenia or schizoaffective disorder in Taiwan. Acta Psychiatrica Scandinavica 2009;120(4):274-80.

[23] Boke O, Aker S, Sarisoy G, et al. Prevalence of metabolic syndrome among inpatients with schizophrenia. The International Journal of Psychiatry in Medicine 2008;38(1):103-12.

[24] Yazici MK, Yağcioğlu AAE, Ertuğrul A, et al. The prevalence and clinical correlates of metabolic syndrome in patients with schizophrenia: findings from a cohort in Turkey. European Archives of Psychiatry and Clinical Neuroscience 2011;261(1):69-78. 